in vivo $34: 667-674(2020)$

doi:10.21873/invivo.11821

\title{
Health-related Quality of Life of Breast Cancer Survivors Attending an Exercise Intervention Study: A Five-year Follow-up
}

\author{
EIJA ROINE ${ }^{1}$, HARRI SINTONEN ${ }^{2}$, PIRKKO-LIISA KELLOKUMPU-LEHTINEN ${ }^{3}$, \\ HEIDI PENTTINEN $^{1}$, MERI UTRIAINEN ${ }^{1}$, LEENA VEHMANEN ${ }^{1}$, RIIKA HUOVINEN ${ }^{4}$, \\ HANNU KAUTIAINEN ${ }^{5,6}$, RIKU NIKANDER ${ }^{7,8}$, CARL BLOMQVIST $^{1}$ and TIINA SAARTO ${ }^{1}$ \\ ${ }^{1}$ Comprehensive Cancer Center, Helsinki University Hospital, \\ and Faculty of Medicine, University of Helsinki, Helsinki, Finland; \\ ${ }^{2}$ Department of Public Health, University of Helsinki, Helsinki, Finland; \\ ${ }^{3}$ Faculty of Medicine and Health Technology, Tampere University, \\ and Cancer Centre, Tampere University Hospital, Tampere, Finland; \\ ${ }^{4}$ Department of Oncology, Turku University Hospital, and Faculty of Medicine, University of Turku, Turku, Finland; \\ ${ }^{5}$ Primary Health Care Unit, Kuopio University Hospital, Kuopio, Finland; \\ ${ }^{6}$ Folkhälsan Research Center, Helsinki, Finland; \\ ${ }^{7}$ Department of Sport and Health Sciences, University of Jyväskylä and GeroCenter \\ Foundation for Aging Research \& Development, Jyväskylä, Finland; \\ ${ }^{8}$ Department of Research \& Education, Central Hospital District of Finland, Jyväskylä, Finland
}

\begin{abstract}
Background/Aim: As the number of breast cancer survivors is increasing, their long-term health-related quality of life (HRQoL) has become an important issue. The aim of the study is to follow up the HRQoL of breast cancer survivors (BCS) in a prospective randomized exercise intervention study and to compare HRQoL to that of the agematched general female population. Patients and Methods: Following adjuvant treatment, 537 patients aged 35-68 and capable of exercise training were randomized to a 12-month exercise trial. In 182 of those patients, HRQoL was measured by the generic 15D at baseline and followed up for five years. Furthermore, the HRQoL of all BCS answering the $15 D$ at five-year follow-up $(n=390)$ was compared to that of a representative sample of the general population. Results: After five years, the BCS' mean HRQoL demonstrated a statistically and clinically significant
\end{abstract}

This article is freely accessible online.

Correspondence to: Eija Roine, Comprehensive Cancer Center, Helsinki University Hospital, P.O.Box 180, 00029 HUS, Helsinki, Finland. Tel: +358 505369778, Fax +358 947174247, e-mail: eija.roine@helsinki.fi

Key Words: Breast cancer, cancer, exercise, general population, health-related quality of life, physical activity, quality of life, rehabilitation, utility. impairment compared to that of the general population (difference -0.023, p<0.001). The mean HRQoL of BCS followed up from baseline until five years did not improve significantly (change=0.007, $p=0.27$ ), whereas the dimensions of usual activities $(0.043, p=0.004)$, depression (0.038, $p=0.007)$, distress (0.030, $p=0.036)$, and sexual activity (0.057, $p=0.009)$ did. Conclusion: The HRQoL of BCS was still impaired five years following treatment.

The prognosis of breast cancer has improved dramatically during the last decades and this, together with an increasing incidence and an aging population, has led to a greater number of breast cancer survivors (BCS) $(1,2)$. The improved prognosis of breast cancer is largely due to early detection with comprehensive screening, and advanced surgical and adjuvant treatments. Adjuvant treatments of breast cancer clearly improve patients' survival, however, effective treatments have severe adverse effects that compromise patients' wellbeing (3-5). Consequently, many BCS suffer from numerous long-term cancer- and treatmentrelated adverse effects and impaired health-related quality of life (HRQoL) even years after the diagnosis and treatment (6-9). With an increasing population of BCS, it is essential to investigate their long-term perceived health and wellbeing and to identify those with impairments in HRQoL to be able to focus on their rehabilitation after breast cancer treatment.

Studies focusing on HRQoL in breast cancer have often used disease-specific instruments $(5,10)$. Disease-specific 
instruments are sensitive in detecting impairments related to the disease and its treatment, while generic HRQoL instruments are intended for use across different diseases and conditions, allowing the comparison of results across all populations. Comparisons to the general population reveal the stress caused by a disease and its treatments. Generic instruments produce a single index utility score, a profile, or both. The utilities produced can be used in health economic analyses and enable the calculation of quality-adjusted life years (QALY) that simultaneously capture gains from the reduced morbidity (quality gains) and reduced mortality (quantity gains), combining them into a single measure (11). QALYs provide a common measure in which diverse outcomes can all be expressed, thus facilitating the comparison of the performance of different programs or interventions in health care.

Physical activity and exercise have been studied widely as forms of rehabilitation following breast cancer adjuvant treatments. According to a meta-analysis and two Cochrane reviews, physical activity may have beneficial effects on the quality of life (QoL) and HRQoL (12-14). The more recent review pointed out, however, that the results published must be interpreted with caution because of the low quality of evidence, and the heterogeneity of interventions and outcome measures in the trials (14).

The BREX (BReast cancer and EXercise) study is a large, open, prospective, multicenter phase III randomized clinical trial investigating the effect of a supervised 12-month exercise intervention on the quality of life (QoL) and bone health in BCS. We have previously reported that at the beginning of the intervention, shortly after the adjuvant treatment, the BCS had worse HRQoL compared to the agestandardized general Finnish female population (15). At the end of the 12-month intervention, the QoL of the BCS, measured by the disease-specific EORTC QLQ-C30, had improved irrespective of the intervention group, and no difference in QoL between the groups was observed at a five-year follow-up $(16,17)$.

In this article we follow-up the BCS' long-term HRQoL, measured by the 15D generic HRQoL instrument, and also compare the BCS' mean HRQoL at five years to that of an age-matched general Finnish female population.

\section{Patients and Methods}

Female BCS $(n=573)$ were enrolled into the BREX study between September 2005 and September 2007. Women aged from 35 to 68 years, who had newly been diagnosed with invasive breast cancer and who had recently completed the adjuvant chemotherapy or started endocrine therapy and/or radiotherapy, were included in the study. Patients who were not capable of training were excluded. The recruitment process and the randomization have already been reported in detail previously $(16,18-20)$. The local Ethical Committee of the Helsinki University Hospital approved the study protocol, and written informed consent was obtained from all participants before entering the study. The trial has been registered in the Helsinki and Uusimaa Hospital District Clinical Trials Register (www.hus.fi) (trial number 210590) and on the clinical trials website http://www.clinicaltrials.gov/ (identifier number NCT00639210).

The medical history of the BCS was assessed at the baseline visit. The patients filled in questionnaires from baseline to the fiveyear follow-up covering QoL, HRQoL, basic demographics and lifestyle habits, and carried out physical performance tests. Information on the amount and intensity of physical activity was collected by a prospective two-week physical activity diary at baseline and thereafter at six follow-up points up to five years. The protocol of clinical examinations, the assessment of physical activity and physical performance tests, as well as the description of the intervention, have been reported in detail previously (16). After the baseline visit, patients were randomly placed either in a one-year supervised exercise training group or in a control group. The exercise intervention consisted of a 12-month weekly supervised aerobic exercise program and instructions for three-times-a-week home exercise. The control group was encouraged to continue their regular exercise habits throughout the study.

HRQoL was measured by the $15 \mathrm{D}$, a generic, 15-dimensional, standardized, self-administered HRQoL instrument that can be used both as a profile and a single index utility score measure (21). The health state descriptive system (questionnaire) is composed of the following dimensions: i) mobility, ii) vision, iii) hearing, iv) breathing, v) sleeping, vi) eating, vii) speech (communication), viii) excretion, ix) usual activities, $\mathrm{x}$ ) mental function, $\mathrm{xi}$ ) discomfort and symptoms, xii) depression, xiii) distress, xiv) vitality, and xv) sexual activity. For each dimension, the respondent chooses one of the five ordinal levels best describing her state of health at the moment (best value $=1$; worst value $=5$ ).

The valuation system is based on an application of the multiattribute utility theory. The single index score (15D score), representing the overall HRQoL on a $0-1$ scale ( $1=$ full health, $0=$ being dead) and the dimension level values, reflecting the goodness of the levels relative to i) no problems on the dimension $(=1)$ and ii) to being dead $(=0)$, are calculated from the health state descriptive system using a set of population-based preference or utility weights. Mean dimension level values are used to draw 15D profiles for groups. The minimum clinically important change or difference in the $15 \mathrm{D}$ score has been estimated to be \pm 0.015 on the basis that people can on average feel such a difference (22). The mean HRQoL of the BCS was compared to that of an age-matched representative sample of the general Finnish female population (754 women) measured in the National Health 2011 Health Examination Survey (23).

After randomization, 36 patients were excluded for not meeting the inclusion criteria ( 33 had osteoporosis, one had metastatic breast cancer, and two had received endocrine treatment for more than four months). Finally, 537 patients were included in the study. The $15 \mathrm{D}$ was incorporated into the study during the second recruitment year and was thus at baseline filled in only by a subgroup $(n=182)$ of the study population. At five years, the data was available for 390 patients: 147 patients were excluded from the five-year analysis: i) 51 due to breast cancer recurrence, ii) 27 discontinued the study, iii) 11 had a new malignancy, iv) 54 did not fill in the $15 \mathrm{D}$ questionnaire, and v) four were excluded for other reasons.

In this article, we report the HRQoL during the follow-up for the 182 BCS for whom HRQoL measurement was available at baseline. Cross-sectional analysis at five years was performed including all 
Table I. Baseline characteristics of the breast cancer survivors ( $n=182)$ included in the baseline to five-year follow-up analyses, and breast cancer survivors $(n=390)$ included in the cross-sectional analysis at five-year follow-up.

\begin{tabular}{|c|c|c|}
\hline Variables & $\begin{array}{l}\text { Baseline } \\
\text { respondents } \\
(\mathrm{n}=182)\end{array}$ & $\begin{array}{l}\text { Five-year } \\
\text { respondents } \\
(\mathrm{n}=390)\end{array}$ \\
\hline Age, years, mean (range) & $52.6(35-69)$ & $53.3(35-69)$ \\
\hline Years of education, mean (SD) & $14.0(3.4)$ & $14.0(3.4)$ \\
\hline \multicolumn{3}{|l|}{ Menopausal status, n (\%) } \\
\hline Premenopausal & $91(50)$ & $171(44)$ \\
\hline Postmenopausal & $91(50)$ & $219(56)$ \\
\hline \multicolumn{3}{|l|}{ Marital status } \\
\hline Married/Co-habiting & $120(66)$ & $259(67)$ \\
\hline Unmarried & $26(14)$ & $50(13)$ \\
\hline Divorced & $31(17)$ & $60(16)$ \\
\hline Widowed & $3(2)$ & $16(4)$ \\
\hline Information missing & $10(1)$ & $3(1)$ \\
\hline \multicolumn{3}{|l|}{ Breast surgery, n (\%) } \\
\hline Mastectomy & $99(54)$ & $199(51)$ \\
\hline Breast conserving surgery & $83(46)$ & $191(49)$ \\
\hline \multicolumn{3}{|l|}{ Axillary operation, $\mathrm{n}(\%)$} \\
\hline SNB & $46(25)$ & $102(26)$ \\
\hline \multicolumn{3}{|l|}{ Adjuvant treatments } \\
\hline Chemotherapy & $172(95)$ & $352(90)$ \\
\hline Radiotherapy & $139(76)$ & $302(77)$ \\
\hline Endocrine treatment & $141(78)$ & $321(82)$ \\
\hline \multicolumn{3}{|l|}{ BMI, n (\%) } \\
\hline$<25$ (normal weight) & $80(44)$ & $175(45)$ \\
\hline 25-30 (overweight) & $74(41)$ & $150(39)$ \\
\hline$>30$ (obese) & $28(15)$ & $65(17)$ \\
\hline
\end{tabular}

SNB: Sentinel node biopsy.

390 BCS who completed the 15D at five-year follow-up. As there was no effect of the exercise intervention on QoL measured by the EORTC-QLQC30 $(16,17)$, the BCS are analyzed here as one group.

The descriptive statistics are presented as means with standard deviations (SD) or as counts with percentages. Statistical comparisons between BCS and the general population were made using the $t$-test. Repeated measures were analyzed using generalizing estimating equation (GEE) models with the unstructured correlation structure. GEE models take into account the correlation between repeated measurements in the same subject; models do not require complete data and can be fit even when individuals do not have observations for all time points. To adjust for multiple testing, Bonferroni correction was applied when appropriate. The normality of variables was evaluated graphically and using the Shapiro-Wilk W test. Stata 16.0 (StataCorp LP, College Station, TX, USA) was used for the analysis.

\section{Results}

The baseline characteristics of the $182 \mathrm{BCS}$ who participated in the follow-up analyses, and of the 390 BCS who were included in the cross-sectional analysis at five-year followup are presented in Table I.

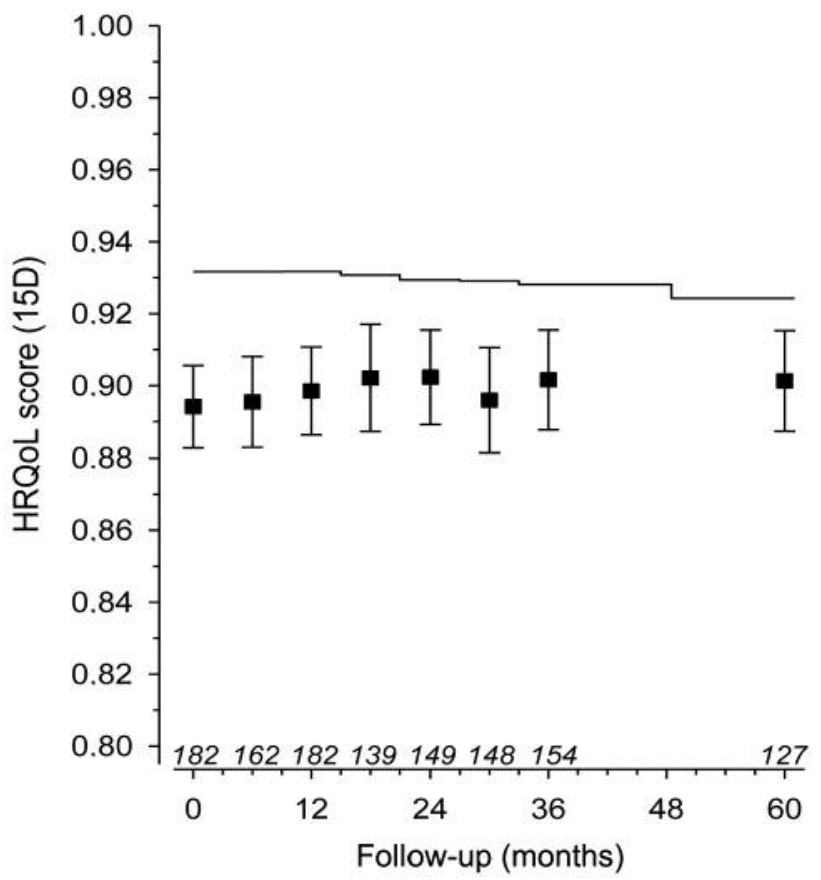

Figure 1. Mean HRQoL scores and 95\% confidence intervals of the breast cancer survivors during the five-year follow-up. The mean HRQoL values of the general population are presented with the solid black line. Above the horizontal axis is the number of survivors (n) that responded at each time point.

HRQoL change during the five-year follow-up. There was no statistically significant or clinically important change in the mean HRQoL score of the BCS during the five-year follow-up [change 0.007 (95\% CI=-0.006 to 0.020), $p=0.27$ ] (Figure 1).

The mean dimension scores of i) usual activities $(0.043$, $95 \% \mathrm{CI}=0.013-0.073, p=0.004)$, ii) depression $(0.038$, $95 \% \mathrm{CI}=0.010-0.066, \quad p=0.007), \quad$ iii) distress $(0.030$, $95 \% \mathrm{CI}=0.002-0.058, p=0.036)$, and iv) sexual activity $(0.057,95 \% \mathrm{CI}=0.015-0.100, p=0.009)$, however, improved significantly during the five years. On the other dimensions, no significant changes were observed (Figure 2).

HRQOL compared to general female population. At five years, the mean HRQoL of BCS ( $n=390)$ was significantly impaired compared to the general population. The HRQoL score for BCS was $0.902(\mathrm{SD}=0.085)$ and for the general population 0.925 (difference $-0.023,95 \% \mathrm{CI}=-0.032$ to $-0.015, p<0.001$ ). The difference is also clinically important.

The BCS were below the general population level on the dimensions of i) sleeping (difference $-0.098,95 \% \mathrm{CI}=-0.128$ to $-0.068, p<0.001$ ), ii) excretion (difference -0.046 $\mathrm{CI}=-0.075$ to $-0.016, p<0.001)$, iii) mental function (difference $-0.049,95 \% \mathrm{CI}=-0.076$ to $-0.022, p<0.001$ ), and iv) sexual activity (difference $-0.099,95 \% \mathrm{CI}=-0.136$ to $-0.061, p<0.001$ ) (Figure 3). 

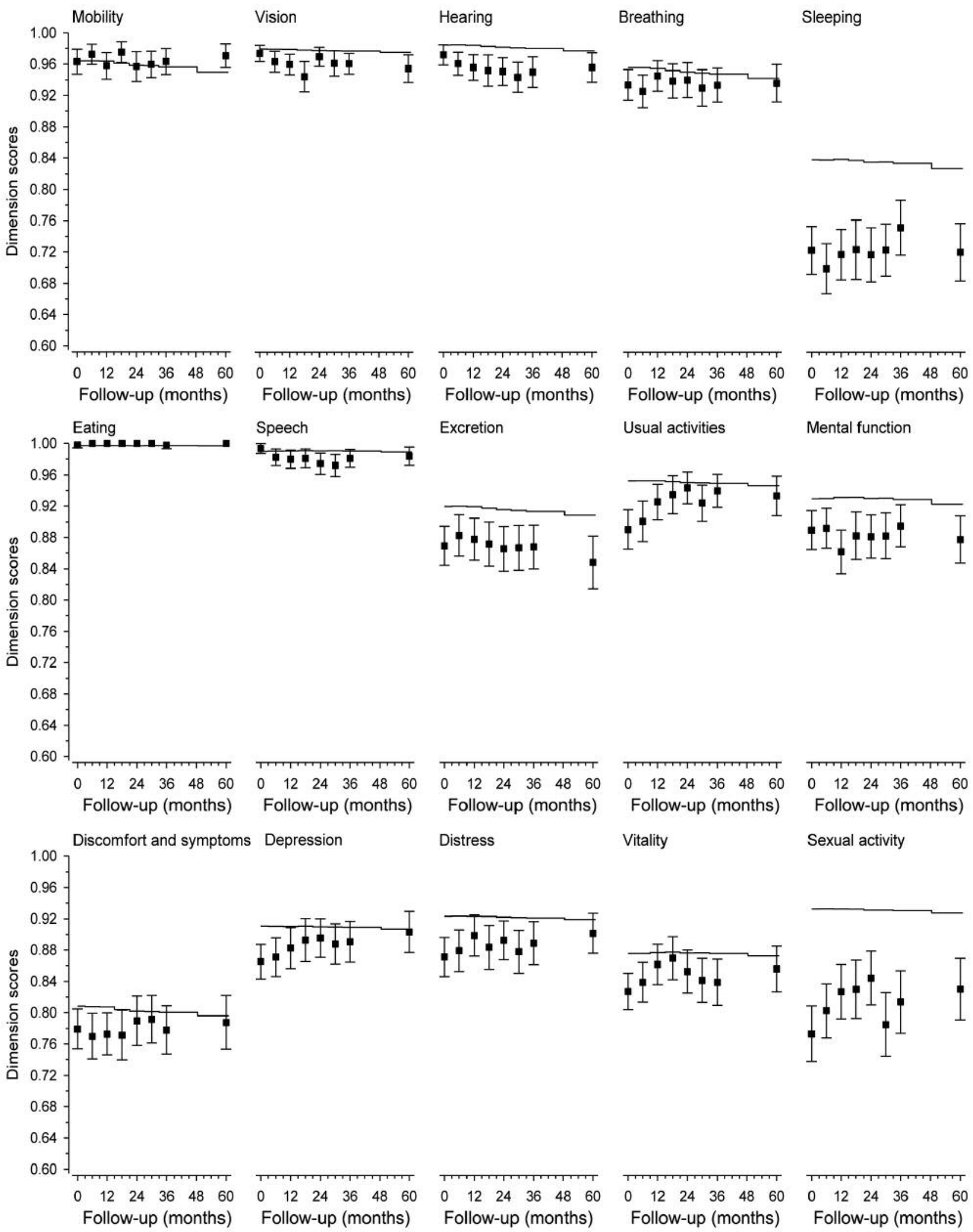

Figure 2. The mean 15D dimension scores and 95\% confidence intervals of the breast cancer survivors during follow-up. The mean values of the general population are presented with a solid black line. 


\section{Discussion}

The BCS experienced a statistically and clinically significantly worse mean HRQoL still five years after adjuvant treatment compared to the age-matched general female population.

There was no statistically significant or clinically important change in the BCS' mean HRQoL during the fiveyear follow-up. On the different dimensions measured by the $15 \mathrm{D}$ instrument, however, some improvement was seen on the dimensions of i) usual activities, ii) depression, iii) distress, and iv) sexual activity from baseline to the five-year follow-up.

We have previously reported, using the disease-specific EORTC-QLQ-C30 instrument, that the QoL of the BCS improves significantly during the first 12 months after the adjuvant treatments and can be maintained thereafter for up to five years $(16,17)$. Similarly, in this study, using the $15 \mathrm{D}$ generic HRQoL instrument, there was a trend towards improved HRQoL during the follow-up, although the change did not reach statistical or clinical significance. The diseasespecific instrument is more likely to detect the acute treatment-related toxicity, which can at least partly explain the difference between the results attained by the instruments.

When compared to the general population, the HRQoL of the BCS measured by the $15 \mathrm{D}$ was impaired throughout the study period and did not reach the general population level even at the five-year follow-up. Similar results on the longterm impairment in QoL and HRQoL have been previously reported, although they have been somewhat conflicting (6$9,24-28)$. Several studies have revealed that especially i) sleep $(6,7,24,27)$, ii) cognitive function $(6,8,24,27-28)$, iii) fatigue $(6,7,27)$, iv) emotional functioning $(6,7,9,26)$ and v) mental health $(6,9,27,29)$ remain impaired years after diagnosis and treatment. In our study, the BCS were worse off compared to the general population on the dimensions of i) sleeping, ii) excretion, iii) mental function, and iv) sexual activity still five years after treatment. On the dimensions of i) usual activities, ii) depression, iii) distress, and iv) sexual activity, BCS improved significantly during the five-year follow-up while no improvement was seen in i) sleeping, ii) excretion and iii) mental function.

A previous exercise intervention study, with a comparable BCS population to ours, compared QoL measured by the EORTC-QLQ-C30 to that of the general population (24). They reported that BCS were worse off in global QoL, and in all functioning and symptom scales during cancer therapy, but global QoL improved and reached the general population level at one-year follow-up. In fact, at five-year follow-up, BCS reported better global QoL and physical functioning and less pain compared to the general population. Impaired cognitive functioning and sleep problems, however, persisted throughout the follow-up (24).

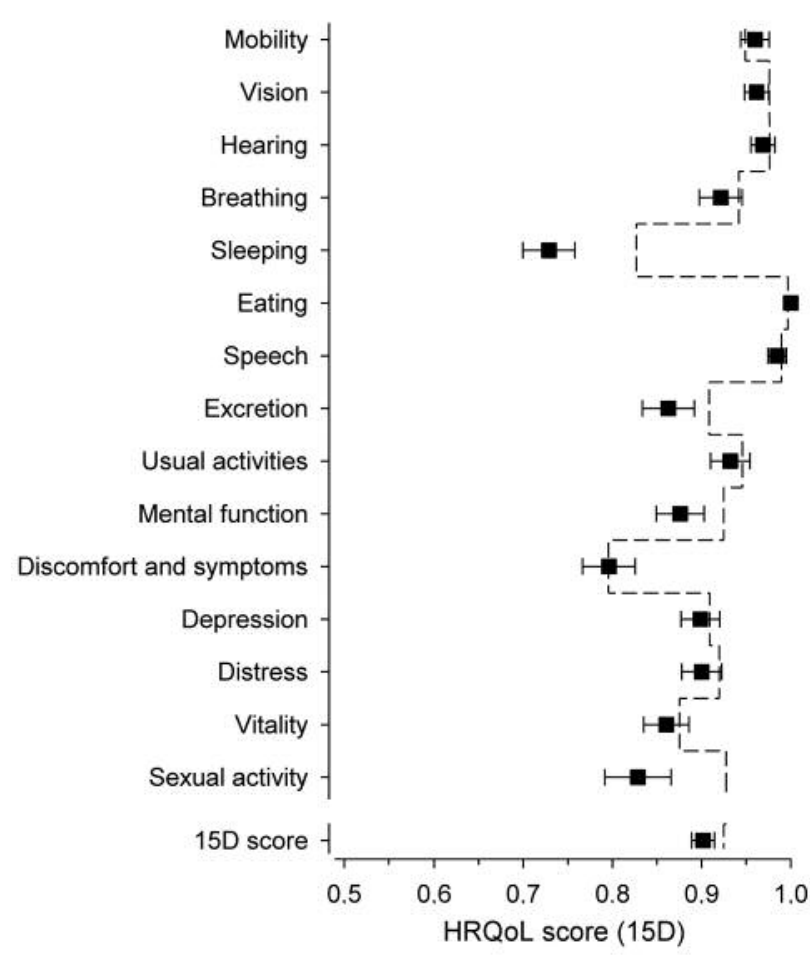

Figure 3. Mean 15D dimension scores and Bonferroni-adjusted confidence intervals for the breast cancer survivors $(n=390)$ at five-year follow-up compared to general female population age-matched levels (dashed line).

A cross-sectional study has revealed that women who had been diagnosed within one year had the worst HRQoL measured by EORTC-QLQ-C30 (8). They were followed by short-term BCS (2-5 years post-diagnosis) who scored worse in all the functioning scales as well as in the global QoL scale compared to age-matched controls. BCS who were 610 years from diagnosis scored worse in some scales but the differences were not of clinical relevance, and BCS ten years after diagnosis were comparable to healthy females (8). Using the generic EQ-5D index score, BCS less than five years after surgery were significantly worse off when compared to general population peers, while over five years from surgery no difference was observed (9). Interestingly, BCS reported more symptoms of pain, anxiety and depression still five years after surgery.

A recent, large study with long-term (5-9 years postdiagnosis) and very-long term ( $\geq 10$ years post-diagnosis) BCS has revealed overall QoL comparable to that of the general population, while significant detriments in almost all functioning and symptom scales existed. BCS had deficits in emotional and cognitive functioning, and persisting insomnia and fatigue measured using the EORTC-QLQC30 (6). Another study with very long-term BCS has also found similar QoL compared to age-matched controls in most 
respects, however, small deficits in cognition and finances were identified using the EORTC-QLQC30 (28). Outcomes derived from the generic 36-Item Short Form Health Survey (SF-36), however, were similar between the BCS and agematched controls (28). A cross-sectional study has reported that BCS were worse off compared to healthy controls on many QoL scales measured using the EORTC-QLQC30 and the SF-36, but the differences decreased with time, and 15 years after diagnosis BCS had QoL comparable to healthy controls. Impairments in cognitive function, insomnia, and mental component summary, however, persisted (27). Another study using the SF-36 has found that very long-term BCS were centered on the general population norms with respect to the physical health status but scored lower on the mental health status (29). Our results are in line with these earlier findings, as especially the dimensions reflecting emotional functioning (e.g. sleeping, mental function) remained impaired for up to five years after adjuvant treatment.

Even though the BCS improved significantly with respect to sexual activity during the five-year follow-up, sexual activity remained at a significantly lower level compared to that of the general population at five years. Earlier studies have reported a high prevalence of sexual dysfunction in BCS, while a recent systematic review revealed that five out of six studies indicate a significantly higher prevalence, risk, or severity of sexual dysfunction in BCS when compared to women without cancer (30). Another recent meta-analysis found that the prevalence of sexual dysfunction is $73.4 \%$ in women with breast cancer (31). In young BCS (<40 years), $68 \%$ of women have reported that two years from diagnosis they have sexual dysfunction in at least one domain (32). In BCS five years from diagnosis, $45 \%$ have reported having some or many challenges in their sexual function (24).

A limitation of our study is that the BCS recruited for this exercise intervention study were younger and healthier compared to BCS in general, because the exclusion criteria included i) age above 68 years and ii) disability to participate in vigorous exercise because of health issues. This limits the generalization of our results but makes our findings even more concerning, because even the somewhat healthier and younger BCS who are willing to participate in an exercise intervention study do not seem to reach the HRQoL level of the general population at five-year follow-up. Earlier studies have revealed an association between physical activity and better HRQoL in BCS $(29,33)$. In addition, an increase in physical activity has been associated with a better QoL among the BREX-study participants when studied by the disease-specific EORTC-QLQC30, both at 12 months and at a five-year follow-up $(16,17)$. Another limitation is that the $15 \mathrm{D}$ questionnaire at baseline was given only to a subgroup of the patients. Thus, the mean HRQoL score at baseline was available for a subgroup only, however, this subgroup did not differ from those not invited to fill in the questionnaire at baseline (data not shown).

The strengths of the study are the long follow-up and the large number of patients for whom HRQoL measurements were available at five years. Moreover, the use of a generic HRQoL instrument providing utilities that can be used in a health economic analysis is another strong point of this study.

We conclude that no significant improvement in the mean HRQoL was seen from baseline to the five-year follow-up, leaving the HRQoL level as clinically importantly below that of the age-matched general female population even at five years after adjuvant treatments. Especially sleeping, mental wellbeing and sexual activity remained at a quality below the general population level, although some improvements were seen on other dimensions.

\section{Conflicts of Interest}

Harri Sintonen is the developer of the 15D instrument.

\section{Authors' Contributions}

Study design: TS (principal investigator), CB (principal investigator), PK-L (Tampere centre principal investigator), RH (Turku centre principal investigator), RN (physical exercise intervention plan). Patient recruitment, follow-up and data collection: HP, LV, MU, PK-L, RH, RN. Analysis and interpretation of data: ER, HK, TS, HS, CB. Written report: ER, HS, TS, HK, CB. Critical revision: all authors.

\section{Acknowledgements}

The writing of this article was supported by a research grant from the Ida Montin foundation. The BREX study was supported by the Cancer Society of Finland.

\section{References}

1 Danckert B, Ferlay J, Engholm G, Hansen HL, Johannesen TB, Khan S, Køtlum JE, Ólafsdóttir E, Schmidt LKH, Virtanen A and Storm HH. NORDCAN: Cancer Incidence, Mortality, Prevalence and Survival in the Nordic Countries, Version 8.2 (26.03.2019). Association of the Nordic Cancer Registries. Danish Cancer Society. Available from: http://www.ancr.nu. Accessed August 30, 2019.

2 Ferlay J, Colombet M and Bray F: Cancer Incidence in Five Continents, CI5plus: IARC CancerBase No. 9 [Internet]. Lyon, France: International Agency for Research on Cancer; 2018. Available from: http://ci5 .iarc.fr. Accessed August 30, 2019.

3 Early Breast Cancer Trialists' Collaborative Group (EBCTCG): Effects of chemotherapy and hormonal therapy for early breast cancer on recurrence and 15-year survival: an overview of the randomised trials. Lancet 365(9472): 1687-1717, 2005. PMID: 15894097. DOI: $10.1016 / \mathrm{S} 0140-6736(05) 66544-0$ 
4 Early Breast Cancer Trialists' Collaborative Group (EBCTCG): Comparisons between different polychemotherapy regimens for early breast cancer: meta-analyses of long-term outcome among 100000 women in 123 randomised trials. Lancet 379(9814): 432-44, 2012. PMID: 22152853. DOI: 10.1016/S0140-6736(11)61625-5

5 Montazeri A: Health-related quality of life in breast cancer patients: A bibliographic review of the literature from 1974 to 2007. J Exp Clin Cancer Res 27(1): 32, 2008. PMID: 18759983. DOI: $10.1186 / 1756-9966-27-32$

6 Doege D, Thong MS-Y, Koch-Gallenkamp L, Bertram H, Eberle A, Holleczek B, Pritzkuleit R, Waldeyer-Sauerland M, Waldmann A, Zeissig SR, Jansen L, Brenner H and Arndt V: Health-related quality of life in long-term disease-free breast cancer survivors versus female population controls in Germany. Breast Cancer Res Treat 175(2): 499-510, 2019. PMID: 30826935. DOI: 10.1007/s10549-019-05188-x

7 Koch L, Jansen L, Herrmann A, Stegmaier C, Holleczek B, Singer S, Brenner H and Arndt V: Quality of life in long-term breast cancer survivors - a 10-year longitudinal populationbased study. Acta Oncol 52(6): 1119-1128, 2013. PMID: 23514583. DOI: $10.3109 / 0284186 X .2013 .774461$

8 Schoormans D, Czene K, Hall P and Brandberg Y: The impact of co-morbidity on health-related quality of life in breast cancer survivors and controls. Acta Oncol 54(5): 727-34, 2015. PMID: 25761088. DOI: 10.3109/0284186X.2014.998277

9 Yu J, Son WS, Lee SB, Chung IY, Son BH, Ahn SH, Jo MW and Lee JW: Uneven recovery patterns of compromised health-related quality of life (EQ-5D-3L) domains for breast Cancer survivors: A comparative study. Health Qual Life Outcomes 16(1): 143, 2018. PMID: 30029669. DOI: 10.1186/s12955-018-0965-0

10 Hashemi SM, Balouchi A, Al-Mawali A, Rafiemanesh H, Rezaie-Keikhaie K, Bouya S, Dehghan B and Farahani MA: Health-related quality of life of breast cancer patients in the Eastern Mediterranean region: a systematic review and metaanalysis. Breast Cancer Res Treat 174(3): 585-596, 2019. PMID: 30632022. DOI: $10.1007 / \mathrm{s} 10549-019-05131-0$

11 Drummond MF: Methods for the Economic Evaluation of Health Care Programmes. Oxford, United Kingdom; New York, USA: Oxford University Press; 2015.

12 Fong DYT, Ho JWC, Hui BPH, Lee AM, Macfarlane DJ, Leung SSK, Cerin E, Chan WYY, Leung IPF, Lam SHS, Taylor AJ and Cheng K: Physical activity for cancer survivors: Meta-analysis of randomised controlled trials. BMJ 344: e70, 2012. PMID: 22294757. DOI: $10.1136 /$ bmj.e70

13 Mishra SI, Scherer RW, Geigle PM, Berlanstein DR, Topaloglu O, Gotay CC and Snyder C: Exercise interventions on healthrelated quality of life for cancer survivors. Cochrane Database Syst Rev (8): CD007566, 2012. PMID: 22895961. DOI: 10.1002/14651858.CD008465.pub2

14 Lahart IM, Metsios GS, Nevill AM and Carmichael AR: Physical activity for women with breast cancer after adjuvant therapy. Cochrane Database Syst Rev (1): CD011292, 2018. PMID: 29376559. DOI: 10.1002/14651858.CD011292.pub2

15 Roine E, Blomqvist C, Kellokumpu-Lehtinen PL, Sintonen H and Saarto T: Health-related Quality of Life in Breast Cancer Patients after Adjuvant Treatments. Breast J 22(4): 473-475, 2016. PMID: 27124555. DOI: 10.1111/tbj.12613

16 Saarto T, Penttinen HM, Sievänen H, Kellokumpu-Lehtinen PL, Hakamies-Blomqvist L, Nikander R, Huovinen R, Luoto R, Kautiainen H, Järvenpää S, Idman I, Utriainen M, Vehmanen L,
Jääskeläinen AS, Elme A, Ruohola J, Palva T, Vertio H, Rautalahti M, Fogelholm M, Blomqvist $\mathrm{C}$ and Luoma ML: Effectiveness of a 12-month exercise program on physical performance and quality of life of breast cancer survivors. Anticancer Res 32(9): 3875-3884, 2012. PMID: 22993332.

17 Penttinen H, Utriainen M, Kellokumpu-Lehtinen P-L, Raitanen J, Sievänen H, Nikander R, Blomqvist C, Huovinen R, Vehmanen L and Saarto T: Effectiveness of a 12-month exercise intervention on physical activity and quality of life of breast cancer survivors; five-year results of the BREX-study. In Vivo 33(3): 881-888, 2019. PMID: 31028212. DOI: 10.21873/invivo.11554

18 Penttinen H, Nikander R, Blomqvist C, Luoto R and Saarto T: Recruitment of breast cancer survivors into a 12-month supervised exercise intervention is feasible. Contemp Clin Trials 30(5): 457463, 2009. PMID: 19394448. DOI: 10.1016/j.cct.2009.04.007

19 Nikander R, Sievänen H, Ojala K, Oivanen T, KellokumpuLehtinen PL and Saarto T: Effect of a vigorous aerobic regimen on physical performance in breast cancer patients - A randomized controlled pilot trial. Acta Oncol 46(2): 181-186, 2007. PMID: 17453366 . DOI: 10.1080/02841860600833145

20 Penttinen HM, Saarto T, Kellokumpu-Lehtinen P-L, Blomqvist C, Huovinen R, Kautiainen H, Järvenpää S, Nikander R, Idman I, Luoto R, Sievänen H, Utriainen M, Vehmanen L, Jääskeläinen AS, Elme A, Ruohola J, Luoma M and Hakamies-Blomqvist L: Quality of life and physical performance and activity of breast cancer patients after adjuvant treatments. Psychooncology 20(11): 1211-1220, 2010. PMID: 20878646. DOI: 10.1002/pon.1837

21 The 15D® health-related quality of life (HRQoL) instrument home page. Available from: http://www.15d-instrument.net/15D

22 Alanne S, Roine RP, Räsänen P, Vainiola T and Sintonen H: Estimating the minimum important change in the $15 \mathrm{D}$ scores. Qual Life Res 24(3): 599-606, 2015. PMID: 25145637. DOI: 10.1007/s11136-014-0787-4

23 Koskinen S, Lundqvist A and Ristiluoma N: Health, Functional Capacity and Welfare in Finland in 2011. National Institute for Health and Welfare (THL), Report 68/2012, 2012. Available from: http://urn.fi/URN:ISBN:978-952-245-769-1. Accessed 21 November, 2019.

24 Schmidt ME, Wiskemann J and Steindorf K: Quality of life, problems, and needs of disease-free breast cancer survivors 5 years after diagnosis. Qual Life Res 27(8): 2077-2086, 2018. PMID: 29740782. DOI: 10.1007/s11136-018-1866-8

25 Matalqah LM, Radaideh KM, Yusoff ZM and Awaisu A: Health-related quality of life using EQ-5D among breast cancer survivors in comparison with age-matched peers from the general population in the state of Penang, Malaysia. J Public Health 19(5): 475-480, 2011. DOI: $10.1007 / \mathrm{s} 10389-$ 011-0406-6

26 Jeffe DB, Pérez M, Liu Y, Collins KK, Aft RL and Schootman M; Quality of life over time in women diagnosed with ductal carcinoma in situ, early-stage invasive breast cancer, and agematched controls. Breast Cancer Res Treat 134(1): 379-391, 2012. PMID: 22484800. DOI: 10.1007/s10549-012-2048-y

27 Klein D, Mercier M, Abeilard E, Puyraveau M, Danzon A, Dalstein V, Pozet A, Guizard AV, Henry-Amar M and Velten M: Long-term quality of life after breast cancer: a French registrybased controlled study. Breast Cancer Res Treat 129(1): 125134, 2011. PMID: 21340477. DOI: 10.1007/s10549-011-1408-3

28 Hsu T, Ennis M, Hood N, Graham M and Goodwin PJ: Quality of life in long-term breast cancer survivors. J Clin Oncol 31(28): 
3540-3548, 2013. PMID: 23980087. DOI: 10.1200/JCO.2012. 48.1903

29 Bouskill K and Kramer M; The impact of cancer and quality of life among long-term survivors of breast cancer in Austria. Support Care Cancer 24(11): 4705-4712, 2016. PMID: 27364151. DOI: 10.1007/s00520-016-3319-7

30 Carreira H, Williams R, Müller M, Harewood R, Stanway S and Bhaskaran K: Associations Between Breast Cancer Survivorship and Adverse Mental Health Outcomes: A Systematic Review. J Natl Cancer Inst 110(12): 1311-1327, 2018. PMID: 30403799. DOI: $10.1093 /$ jnci/djy 177

31 Jing $\mathrm{L}$, Zhang $\mathrm{C}$, Li $\mathrm{W}$, Jin $\mathrm{F}$ and Wang $\mathrm{A}$ : Incidence and severity of sexual dysfunction among women with breast cancer: a meta-analysis based on female sexual function index. Support Care Cancer 27(4): 1171-1180, 2019. PMID: 30712099. DOI: $10.1007 / \mathrm{s} 00520-019-04667-7$
32 Ljungman L, Ahlgren J, Petersson L-M, Flynn KE, Weinfurt K, Gorman JR, Wettergren L and Lampic C: Sexual dysfunction and reproductive concerns in young women with breast cancer: Type, prevalence, and predictors of problems. Psychooncology 27(12): 2770-2777, 2018. PMID: 30203884. DOI: 10.1002/pon.4886

33 Glaser AW, Fraser LK, Corner J, Feltbower R, Morris EJ, Hartwell G, Richards M and Wagland R: Patient-reported outcomes of cancer survivors in England 1-5 years after diagnosis: a cross-sectional survey. BMJ Open 3(4): e002317, 2013. PMID: 23578682. DOI: 10.1136/bmjopen-2012-002317

Received November 21, 2019

Revised December 3, 2019

Accepted December 10, 2019 